\title{
Christopher Alexander's A Pattern Language: analysing, mapping and classifying the critical response
}

\author{
Michael J. Dawes ${ }^{*}$ (D) and Michael J. Ostwald (D)
}

\begin{abstract}
A Pattern Language by Christopher Alexander is renowned for providing simple, conveniently formatted, humanist solutions to complex design problems ranging in scale from urban planning through to interior design. This text is also believed to be the most widely read architectural treatise ever published. Despite this, there is also little acknowledgement in its popular reception that it is only one part of a trilogy of works documenting Alexander's 'second theory' of architecture. Thus, while A Pattern Language is widely referenced in architectural scholarship, most of these references simply acknowledge its existence and fail to engage with its content. Furthermore, the literature that does critically engage with Alexander's theory, challenging its ideas and assumptions, is often difficult to find, and the criticisms are diverse and complex. The intent of this paper is to facilitate a deeper understanding of these criticisms and the relationships between them. The 28 criticisms identified in past research are organised hierarchically in this paper into three tiers representing those associated with the: (i) conceptualisation, (ii) development and documentation and, (iii) implementation and outcomes of Alexander's theory. The relationships between these criticisms are then mapped diagrammatically thereby forming the basis for thematic groupings within each hierarchical tier. This organisation reveals that only two criticisms relate to the concept of pattern languages in isolation, while the remainder arise, directly or indirectly, from Alexander's idiosyncratic ontological and epistemological positions. The conclusion analyses the relationships between the criticisms to develop a holistic and understanding of where the problems in Alexander's theory might lie.
\end{abstract}

Keywords: Christopher Alexander, A Pattern Language, The Timeless Way of Building, The Oregon Experiment, Design method, Critical response

\section{Introduction}

Massive social, technical and economic changes during the nineteenth century provided the catalyst for the rise of modernism in architecture, and the creation of some of the world's most iconic buildings. However, the relentless pursuit of the modernist aesthetic also produced examples of uncomfortable and inhospitable spaces. Christopher Alexander was amongst the most vocal critics of these spaces and responded to them by devoting his career to developing three unique and closely related theories of architectural and urban design. This paper focuses

*Correspondence: michael.dawes@uon.edu.au

School of Architecture and Built Environment, University of Newcastle, University Drive, Callaghan, NSW 2308, Australia on Alexander's 'second theory' of architecture, which appeared in the form of three canonical texts, The Timeless Way of Building (Alexander 1979), A Pattern Language (Alexander et al. 1977), and the Oregon Experiment (Alexander et al. 1975). It must be noted that Alexander's research actually constitutes a single, slowly evolving theory of architecture that spans his entire career. However, these three texts represent a stable, middle stage in Alexander's research and collectively provide a sufficiently self-contained set of ideas to be described (for the ease of the following discussion) as his 'second theory?.

Alexander's second theory is significant for its attempt to facilitate a paradigm shift in architecture that would replace the conventional, subjective and explanatory, 
theory with an objective, evidence-based, theory that directly generates a design (Grabow 1983; Gelernter 2000). A Pattern Language is significant for demystifying complex socio-spatial considerations through a simple building block format which makes this content accessible to non-professionals, and is one reason why this text is believed to be the most widely read architectural treatise ever published (Lea 1994; Alexander 1996; Kohn 2002; Saunders 2002b; Hermann 2004; Mehaffy 2008; Silva and Paraizo 2008). A Pattern Language is also credited with inspiring the development of the objectoriented programming languages used to create the majority of current computer software in addition to partially inspiring the New Urbanist movement.

Despite the influence and impact of Alexander's second theory, it has been rejected or ignored by many architects, and many academic references to the theory simply acknowledge its existence rather than attempting to engage with its ideas. Nevertheless, the scholars who do engage with the theory have identified substantial flaws, many of which are difficult to untangle without a substantial loss of meaning (Dovey 1990). Indeed, several of the criticisms cited are acknowledged, if not accepted, by Alexander, as part of various counterarguments he offers. Furthermore, despite the proselytising tone of $A$ Pattern Language, its introductory discussion states that it was published as a work in progress and encourages readers to continue to refine the patterns contained therein and develop their own new patterns.

Thus, Alexander's second theory of architecture is relatively poorly understood and this paper is dedicated to bringing clarity to the myriad of criticisms levelled against it. In undertaking this endeavour, 28 criticisms are identified and organised into three hierarchical levels corresponding to the (i) conceptual foundations of the theory, (ii) its development and documentation, and (iii) its implementation and outcomes. Criticisms are also organised thematically and diagrammatically to reveal how they relate to each other. Through this process the paper differentiates between criticisms of pattern languages in general, and those which are levelled specifically at Alexander's work.

\section{Background}

Christopher Alexander's 'first theory' of architectural beauty was presented in his Harvard doctoral thesis and later published as Notes on the Synthesis of Form (Alexander 1964). The inspiration for this work is Alexander's belief that the buildings of traditional societies are inherently more beautiful than contemporary architecture. Alexander alleges that this disparity arises from the use of radically different design processes. Traditional buildings are the product of a communally-shared value system and piecemeal adaptation to changing circumstances which brings all the 'forces' impacting a design into a harmonious balance. In contrast, contemporary architecture results from the imposition of formal rules and abstract concepts upon a single design episode, creating an outcome where the 'forces' are unbalanced. Alexander's solution to this problem was a complex mathematical method for balancing all the 'forces' impacting a design. When applied in practice, Alexander discovered that this process was too demanding for all but the largest design projects. However, Alexander also discovered that particular ensembles of 'forces' encapsulated generic situations that occurred repeatedly throughout the built environment, and that resolving these forces would yield generic solutions that could be adapted to an infinite variety of specific circumstances (Broadbent 1980; Grabow 1983). In order to pursue this line of thinking, Alexander secured funding to establish the Centre for Environmental Structure and the concept of predefined generic solutions evolved to become the 'patterns' in his 'second theory' of architecture (Clavan 1979; Grabow 1983; Kohn 2002; Veloso 2014).

Alexander's second theory, itself a collaborative process, was developed across three canonical books; The Oregon Experiment (Alexander et al. 1975), A Pattern Language (Alexander et al. 1977) and The Timeless Way of Building (Alexander 1979). Collectively these three works constitute one of the 1960s and 1970s most sustained criticisms of modernism. During this era Bernard Rudofsky's Architecture Without Architects (Rudofsky 1964), and Amos Rapoport's House, Form and Culture (Rapoport 1969) and The Meaning of the Built Environment (Rapoport 1982) argued that intuitive and unconscious processes were vital components of traditional and vernacular architecture (Kohn 2002; Bhatt 2010). In a similar vein, Kevin Lynch's The Image of the City (Lynch 1960) and Jane Jacobs's The Death and Life of Great American Cities (Jacobs 1961), focused on the importance of cognitive cohesion, vitality and piecemeal growth as part of a vibrant built environment (Kohn 2002; Bhatt 2010). All of these concepts were central to Alexander's second theory of architecture, which again focused on the inherent beauty of traditional urban spaces and buildings.

Alexander believes " $t \mathrm{t}]$ here is a central quality which is the root criterion of life and spirit in a man, a town, a building, or a wilderness. This quality is objective and precise, but it cannot be named" (Alexander 1979, p 19). The first volume of Alexander's theory-The Timeless Way of Building-details his belief that this unnamed quality is the source of the inherent beauty of traditional architecture. Here it is argued that the shared values and customs of traditional societies provide a guiding framework, or design language, that restrains the many small 
acts of individual construction and integrates them into a larger cohesive environment. Despite being unnamed, Alexander proposed several descriptors for this quality'beauty', 'alive', 'whole, 'comfortable', 'free, 'exact', 'egoless', and 'eternal'-and discusses how each captures certain dimensions of the quality, even though they are too imprecise to describe it perfectly.

Alexander argues that this quality exists, to some extent, in every individual, and this allows us to recognise its presence in the environment and each other. Thus, "the central scientific fact" (Alexander 1979, p 54) of Alexander's second theory of architecture is that a strong reciprocal relationship exists between environments and their inhabitants. The theory states that places which exhibit this quality will awaken it in people, and people who have found the quality will embed it into the places they help to create. Both people and places will become healthy, alive, whole, and self-maintaining if they have the 'quality without a name', and will be 'sick', 'dead', unwhole, and self-destroying without it.

According to Alexander the 'quality without a name' is only created when people employ the timeless way of building. This requires an 'activated populace' who participate in shaping their environment through a democratic process based on common traditions, a shared design language and a society-wide dialogue. However, Alexander also argues that the traditional languages and values that once guided this process have been lost over time, or else have become so corrupted as to be utterly dysfunctional (Salingaros 2000). Therefore, the second volume of the trilogy, A Pattern Language was intended to redress this issue by providing a replacement design language which forms the functional basis of Alexander's theory.

A Pattern Language details 253 patterns which serve as generic guiding principles for design. "Each pattern describes a problem which occurs over and over again in our environment, and then describes the core of the solution to that problem, in such a way that you can use this solution a million times over, without ever doing it the same way twice" (Alexander et al. 1977, p x). Patterns range in scale from regional planning through to interior design, and adapting their solutions to local circumstances and synthesising those into larger designs, ensures that all forces are balanced in a way that facilitates the emergence of 'quality without a name.' In order to enable this synthesis, each pattern in the language follows a consistent format of five sections. First is its identification, including name, number, confidence rating, and a photograph of a typical example. Second is a list of connections to other patterns it helps to complete. The third section comprises a description of the context in which the pattern is relevant and the empirical evidence that supports it. The fourth section prescribes and diagrams the actions required to ensure the emergence of the 'quality without a name' and the final section is a list of other patterns that help to complete it.

Alexander's third volume-The Oregon Experimentoutlines the application of this theory in the design of a campus for the University of Oregon. This text focuses primarily on bureaucratic processes that are required to ensure that small scale projects and piecemeal development can occur in large scale projects for a single client.

Ultimately however, Alexander rejected his second theory of architectural beauty as he felt it had too little generative power and too little focus on geometry. Three decades later he proposed a 'third theory' of beauty, which replaced patterns with the generic concept of 'centres' and their transformations, in addition to removing much of the neatly packaged social and architectural content that makes his second theory so compelling (Alexander 2002b, c, 2004, 2005; Adams and Tiesdall 2007). Despite rejecting his own second theory, it remains his Alexander's most well-known work, and it continues to have an enduring influence and impact to the present day (Lea 1994; Alexander 1996; Saunders 2002b; Hermann 2004; Mehaffy 2008; Silva and Paraizo 2008).

\section{Criticisms of Alexander's second theory of architecture}

The following sections review the criticisms of Alexander's second theory of architecture. Many of these criticisms focus on A Pattern Language, while others also address problems found in The Timeless Way of Building and The Oregon Experiment. The intent of this paper is to facilitate a deeper understanding of Alexander's second theory by explaining and classifying these criticisms and then mapping the relationships that exist between them. Therefore, each criticism is assigned a number [\#] and organised into a three-tiered hierarchy corresponding to the conceptualisation, development, and implementation of Alexander's theory. Criticisms are further organised into thematic groupings within each tier and the relationships between patterns signified by listing the number of any antecedent $[\mathrm{A \#}]$ and subsequent $[\mathrm{S \#}]$ criticisms. This is significant because many of the criticisms are founded on, or lead to, other critical responses. However, it is also important to realise that these antecedent $[\mathrm{A \#}]$ and subsequent $[\mathrm{S \#}]$ links, are determined by the scale and logic of the criticism, not the date when the criticism was published, or any references it might make to other critical scholarship. Furthermore, the complex interrelationships between these criticisms of Alexander's theory are said to be difficult to untangle without a significant loss of meaning (Dovey 1990), and thus the following discussion represents only one possible mapping of these criticisms and 
their relationships. As this process has never been undertaken before, this mapping may also provide a starting point for future, alternative approaches to understanding the possible limitations of Alexander's theory.

The procedure for evaluating and mapping criticisms involves three stages. First, a literature review to identify criticisms. Second, an examination and classification of the criticisms. Third, identifying and mapping the connections between criticisms.

The first stage of this research involves an extensive review of literature discussing Alexander's work. While the focus of the present research is Alexander's second theory, the literature search includes research relating to Alexander's broader body of work as it often includes, and provides insight into, the criticisms of his second theory.

The second stage examines the criticisms and classifies them into one of three hierarchical tiers, and where applicable, organises them into thematic groups. The highest tier contains criticisms related to the conceptualisation of Alexander's theory and includes those associated with his idiosyncratic ontological and epistemological positions. The second tier focuses on criticisms relating to the actual development of his second theory and comprises three thematic groups relating to scholastic standards, the testing of patterns, and the reasoning supporting his decisions. The final or lowest tier documents criticisms relating to the implementation of the theory including claims that it is overly controlling, flawed, and unsuccessful. The three tiers which make up this classification system are not predetermined; rather they emerge organically from the criticisms which often focus on one of these aspects of Alexander's theory.

There are, however, several criticisms which are broad enough in scope to include aspects of more than one tier. An example of such a criticism is the argument that Alexander's theory often excludes non-western examples of architecture. Some of the literature discussing this criticism points to this tendency as evidence of a limiting ontology that impacts the conceptualisation of the theory. Other literature describes how this limitation impacts the development of Alexander's theory, and results in some patterns being based on faulty evidence and argumentation. The more exhaustive literature discusses both of these considerations. Therefore the following classification of criticisms split such considerations among the relevant tiers in order to facilitate the discussion of each aspect within the context of similar criticisms, at the risk of giving the appearance that some arguments recur throughout the text.

Within each hierarchical tier, criticisms are organised into thematic groupings representing broader concepts intended to facilitate discussion and understanding.
These groupings also emerge organically from the examination of the individual criticisms. For example the 'scholarship' group includes criticisms which together may facilitate a discussion about scholarly writing quality in the context of Alexander's second theory. In this way, mapping and classifying the criticisms of Alexander's theory provides greater understanding of the theory.

The final stage of this procedure identifies and maps the antecedent and subsequent connections between criticisms and demonstrates that many criticisms of Alexander's theory have roots in his idiosyncratic ontological and epistemological positions. The phenomenon wherein several broad criticisms broach multiple hierarchical levels, offers a useful starting point for this mapping. In other cases, the literature discusses similar criticisms in the context of different hierarchical levels which provides a basis for mapping, while in a small number of cases a direct logical connection means that if the higher criticism occurs then the lower criticism also occurs. Regardless of which approach informs the identification of antecedent and subsequent criticisms, the decision regarding whether a connections exists is based on an interpretative analysis rather than a quantifiable metric. In some cases one criticism is the antecedent of a single criticism within a thematic group and in other cases one criticism is the antecedent of the entire group. These differences are represented in the diagrams by the connecting arrow either pointing to the circle containing a criticism number or the arrow pointing to the dotted outline of a thematic group.

The following sections present the criticisms identified from the literature. In each hierarchical tier the criticisms are grouped, discussed, any antecedent and subsequent criticisms identified, and presented in diagrammatic and tabular form.

\section{Conceptualisation criticisms}

There are four major criticisms of the conceptual foundations of Alexander's second theory of architecture (Table 1). These are raised separately by 15 scholars, and in several cases Alexander, or one of his co-authors, has responded to these criticisms providing a counterpoint to consider. Three of these criticisms $[1,2,3]$ are ontological in nature and are closely associated with his exclusive or inflexible world-view, whereas the last [4] is epistemological and relates to the legitimisation of his theory (Fig. 1).

The first ontological issue with the conceptualisation of Alexander's theory focuses on his rejection of pluralist values [1] and subjective world-view, in favour of a singular and objective one. This universalising tendency is seen in his description of the 'quality without a name'. In The Timeless Way of Building (Alexander 1979), Alexander refers to this quality as 'the great self' or 'the void' and 
Table 1 Criticisms of Alexander's second theory of architecture: conceptualisation

\begin{tabular}{|c|c|c|c|c|c|}
\hline [\#] & Issue & A\# & Criticism & S\# & Source \\
\hline 1 & Ontology & - & $\begin{array}{l}\text { Rejecting pluralistic values confuses } \\
\text { subjective and objective phenomena }\end{array}$ & 3 & (Saunders 2002a, 2003; Bhatt 2010) \\
\hline 2 & Ontology & - & $\begin{array}{l}\text { Alternate experiences and social, politi- } \\
\text { cal and economic realities are incom- } \\
\text { patible with Alexander's world view }\end{array}$ & 3 & $\begin{array}{l}\text { (Montgomery 1970; Broadbent 1980; } \\
\text { Davis 1983; Dovey 1990; Salingaros 2000, } \\
\text { Elsheshtawy 2001; Kohn 2002; Saunders } \\
\text { 2002a; Walker 2003; Mehaffy 2008; Bhatt } \\
\text { 2010; Kalb 2014) }\end{array}$ \\
\hline 3 & Ontology & 1,2 & $\begin{array}{l}\text { The timeless way of building is the only } \\
\text { valid means for creating beautiful } \\
\text { environments }\end{array}$ & $\begin{array}{r}10,11,12,13,15,16 \\
17,18,19,20,21,22\end{array}$ & $\begin{array}{l}\text { (Broadbent 1980; Protzen 1980; Dovey 1990; } \\
\quad \text { Lang 1994) }\end{array}$ \\
\hline 4 & $\begin{array}{l}\text { Epistemol- } \\
\text { ogy }\end{array}$ & - & $\begin{array}{l}\text { Alexander's definition of 'science' } \\
\text { excludes many tenets of scholarly } \\
\text { research }\end{array}$ & $\begin{array}{l}5,6,7,8,9,10,11,12,13 \\
\quad 14,18\end{array}$ & (Alexander 2002a,b; Saunders 2002a) \\
\hline
\end{tabular}

[\#], criticism identifier; \#A, antecedent criticism; \#S, subsequent criticism
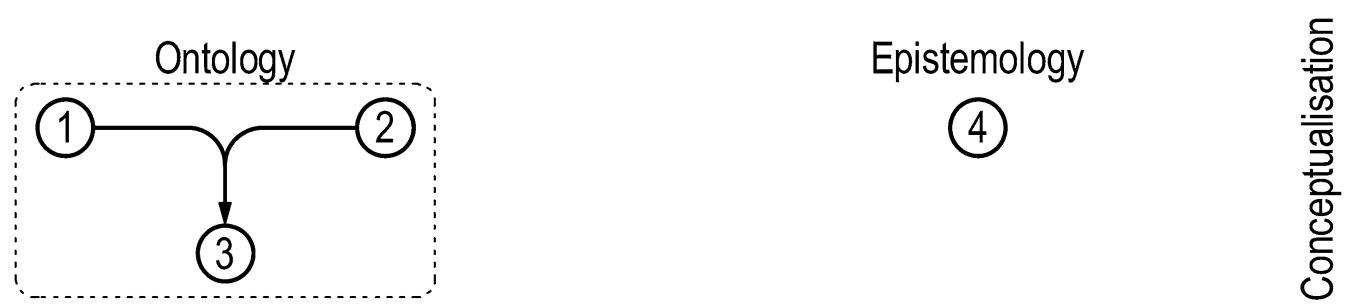

Fig. 1 Criticism connections and groupings of Alexander's second theory of architecture: conceptualisation. Numbers correspond to criticism numbers in text and tables, dotted lines indicate groups and sub-groups of criticisms, arrows point from antecedent criticisms to secondary criticisms or groups of criticisms

argues that it is present, to some extent, in every individual, whilst being much more prevalent in traditional and pre-enlightenment societies. This fundamental and supposedly universal quality has clear parallels with theological values leading to the suggestion that Alexander's world view is inspired by a mystical experience (Broadbent 1980). Furthermore, the very idea that all humanity shares an innate and common value system is deeply problematic. Values and attitudes are developed and learnt through a combination of human sensory engagement, education, and enculturation. Indeed, human experience, which is a core system for the development of values, is necessarily individual. Yet, problematically, Alexander assumes that all people experience the same response to a given stimulus (Dovey 1990; Kohn 2002). Adopting this ontological position allows Alexander to claim that certain environments are objectively superior to others-that beauty is an objective fact-and therefore any disputes over personal opinion, taste or aesthetic preference are resolved by appealing to this single value (Kohn 2002).

The second concern with Alexander's theory is the limiting effect of a romanticised world-view, which denies the existence of alternative lifestyles and architectural influences [2]. Alexander's ideal lifestyle is "comfortable, easygoing, sensuously pleasurable, communal, and full of leisure time for socializing and solitude" (Saunders 2002a, p 94). This lifestyle specifically excludes any form of external controls, inhibitions, rules, morals, or fears. While this utopian vision informs the basis for the patterns in his language, it also excludes many social, political and economic realities (Elsheshtawy 2001). Furthermore, Alexander's ontology blinds him to the possibility that not everybody aspires to this lifestyle (Broadbent 1980; Saunders 2002a, 2003; Bhatt 2010). With these views as crucial precursors to his theory, Alexander is effectively forced to condemn or reject experiences or desires that failed to conform (Saunders 2002a). Thus, Alexander rejects his own architectural training, prototype patterns developed by students, and idiosyncratic contemporary architecture, all of which he summarily dismisses as 'absurd' (Alexander 1979; Kohn 2002; Saunders 2002a). This 'disturbing narrowness'particularly regarding economic realities and the willingness to reject the preferences of others-is an integral component of Alexander's conceptualisation of beauty (Montgomery 1970). This exclusive quality also extends to the architectural works Alexander cites as examples of 
good design which are drawn almost entirely from either Medieval Europe or his own work (Kalb 2014), the latter of which is said to resemble "the hodgepodge stone, halftimber, and clapboard houses of southern England, where he grew up" (Kohn 2002, p 34).

The third ontological problem with Alexander's theory is the concept that beautiful environments can only be created through the timeless way of building [3]. This can be understood as a particularly problematic combination of the previous two criticisms $[1,2]$ wherein Alexander's personal preferences become the only objective standard of beauty, and anyone with alternative preferences is dismissed as suffering some form of 'mental defect' (Alexander and Eisenman 1982). Alternately Alexander effectively discounts such views as coming from victims of 'mass psychosis', or people who are 'brainwashed', thereby explaining their inability to see the obvious and objective truth of his pronouncements (Davis 1983; Dovey 1990; Kohn 2002; Saunders 2002a). This inflexible proposition is the source of many damning criticisms of the development and implementation of Alexander's theory. However, several of these criticisms are partially negated by one sentence in the preface to A Pattern Language which notes that its content represents only "one possible pattern language" (Alexander et al. 1977, p x) and Alexander encourages readers to refine his patterns and develop new ones. However, confusingly, this preface also offers the counterview that,

"[E]very society that is alive and whole, will have its own unique and distinct pattern language; and further, that every individual in such a society will have a unique language, shared in part, but which as a totality is unique to the mind of the person who has it. In this sense, in a healthy society there will be as many pattern languages as there are people-even though these languages are shared and similar"(Alexander et al. 1977, p xvi).

Thus, a multitude of patterns and languages are possible, however, as every whole society has a pattern language, the only way to create a vibrant and beautiful society is by following the timeless way of building, as facilitated by pattern languages. Any alternate means of shaping society could never produce the quality without a name, thus there is only one 'right' way of building.

The final problem with the conceptualisation of Alexander's theory relates to his epistemological position, particularly his idiosyncratic definition of 'science' [4] and subsequent claims that his theory is 'scientific'. Alexander's response to a review of his later works provides a particularly enlightening statement regarding the difference between 'real science' and 'phony social science' which merely resembles scientific inquiry;
"You are doing science when you figure out how something works. Especially, if you figure out something that people have not figured out before. You don't need to dress it up, you just need to work it out. All the rest is dressing. Pompous language, format of summary and text and findings, footnotes, erudite references, carefully marshaled precedents-all those are the trappings of science, the appearance of science, not science itself" (Alexander 2002a, $p$ 3).

Thus, so far as Alexander is concerned, science is the process of 'figuring something out' while the documentation of that discovery is largely irrelevant. Therefore, the "material in The Phenomenon of Life and the material in A Pattern Language 25 years earlier are both science" (Alexander 2002a, p 3). This later claim might be true, provided you accept Alexander's work as a series of hypotheses (the desire to 'figure something out'), rather than proven facts which is the position adopted and recommended in the best known attempt to empirically evaluate one of Alexander's patterns (Kaplan et al. 1987). This interpretation of Alexander's work is alluded to in the preface of A Pattern Language which states that "each pattern may be looked upon as a hypothesis, like one of the hypotheses of science" (Alexander et al. 1977, p xv). However, the problems inherent in Alexander's definition of science are attenuated when they are used to present the development and documentation of A Pattern Language, because his use of 'science' and scientific terms imply that Alexander's pronouncements are proven facts rather than mere hypotheses. In this sense Alexander's work has been said to be trapped between structuralist and phenomenological world views (Elsheshtawy 2001; Kalb 2014). The following section details the criticisms levelled against the development and documentation of Alexander's theory and demonstrates how many of these criticisms emerge from the problems [1-4] discussed previously.

\section{Development and documentation criticisms}

Following the publication of his second theory, Alexander bemoaned a lack of engagement from architectural and design professionals which might be partially explained by criticisms of the development and documentation of this theory (Kohn 2002). The barriers preventing architects from engaging with Alexander's theory can be broadly categorised into three groups (Table 2). The first group $[5,6,7,8,9,10,11,12]$ arise from Alexander's idiosyncratic understanding of 'science' (4) and subsequent issues including an absence of explicit definitions which makes practical engagement with the theory difficult. The second group $[9,13,14]$ focus on Alexander's ambivalent use of the term 'empirical' to describe 
Table 2 Criticisms of Alexander's second theory of architecture: development and documentation

\begin{tabular}{|c|c|c|c|c|c|}
\hline [\#] & Issue & $\# \mathbf{A}$ & Criticism & \#S & Source \\
\hline 5 & $\begin{array}{l}\text { Scholarship-documenta- } \\
\text { tion }\end{array}$ & 4 & $\begin{array}{l}\text { The definitions of 'patterns' and 'forces' are } \\
\text { inexplicit }\end{array}$ & - & (Lea 1994; Silva and Paraizo 2008) \\
\hline 6 & $\begin{array}{l}\text { Scholarship-documenta- } \\
\text { tion }\end{array}$ & 4 & $\begin{array}{l}\text { Exemplars of good design are difficult to } \\
\text { comprehend }\end{array}$ & - & (Kohn 2002) \\
\hline 7 & $\begin{array}{l}\text { Scholarship-documenta- } \\
\text { tion }\end{array}$ & 4 & $\begin{array}{l}\text { The efforts and insights of scholars developing } \\
\text { similar themes are rarely acknowledged }\end{array}$ & - & (Broadbent 1980; Elsheshtawy 2001; Kohn 2002) \\
\hline 8 & $\begin{array}{l}\text { Scholarship-documenta- } \\
\text { tion }\end{array}$ & 4 & $\begin{array}{l}\text { Explanations of pattern synthesis and lan- } \\
\text { guage structure are inadequate }\end{array}$ & - & (Salingaros 2000) \\
\hline 9 & $\begin{array}{l}\text { Testing } \\
\text { Scholarship_documenta- } \\
\text { tion }\end{array}$ & 4 & $\begin{array}{l}\text { Greater numbers of patterns were never } \\
\text { proven to produce superior environments }\end{array}$ & 25,27 & \\
\hline 10 & Scholarship_presentation & 3,4 & $\begin{array}{l}\text { Deliberately provocative statements damage } \\
\text { Alexander's credibility }\end{array}$ & - & (King 1993; Kohn 2002) \\
\hline 11 & Scholarship_presentation & 3,4 & $\begin{array}{l}\text { Universal and dogmatic statements discour- } \\
\text { age engagement and criticism }\end{array}$ & - & $\begin{array}{l}\text { (Broadbent 1980; Protzen 1980; Kohn 2002; } \\
\text { Messina 2003; Walker 2003; Bhatt 2010) }\end{array}$ \\
\hline 12 & Scholarship_presentation & 3,4 & $\begin{array}{l}\text { The canonical texts physically resemble bibles } \\
\text { and imply authority that discourages criti- } \\
\text { cism }\end{array}$ & - & (Broadbent 1980; Dovey 1990) \\
\hline 13 & Testing & 3,4 & $\begin{array}{l}\text { Patterns are driven by ideology and based on } \\
\text { faulty evidence, or non-rigorous reasoning }\end{array}$ & $23,24,25$ & $\begin{array}{l}\text { (Montgomery 1970; Broadbent 1980; Protzen } \\
\text { 1980; Dovey 1990; Salingaros 2000; Kohn 2002; } \\
\text { Saunders 2002a; Bhatt 2010) }\end{array}$ \\
\hline 14 & Testing & - & Patterns may be impossible to rigorously test & - & (Protzen 1980; Salingaros 2000) \\
\hline 15 & Logic and reasoning & 3 & $\begin{array}{l}\text { Informational fallacies protect the theory from } \\
\text { contrary information and experience }\end{array}$ & 21 & (Protzen 1980) \\
\hline 16 & Logic and reasoning & 3 & $\begin{array}{l}\text { The theory's pre-industrial procurement strat- } \\
\text { egy is unsuitable for modern societies }\end{array}$ & 23 & (Gelernter 1983; Elsheshtawy 2001) \\
\hline 17 & Logic and reasoning & 3 & $\begin{array}{l}\text { Alexander espouses pure freedom but } \\
\text { demands adherence to his rules }\end{array}$ & - & $\begin{array}{l}\text { (Broadbent 1980; Protzen 1980; Saunders 2002a; } \\
\text { Walker 2003) }\end{array}$ \\
\hline 18 & Logic and reasoning & 3,4 & $\begin{array}{l}\text { Alexander pursues traditional design through } \\
\text { anti-traditional means }\end{array}$ & - & (Kalb 2014) \\
\hline 19 & Logic and reasoning & 3 & $\begin{array}{l}\text { The populace have compromised taste due } \\
\text { to modernist brainwashing but also prefer } \\
\text { Alexander's designs }\end{array}$ & - & (Bornstein 2005/2006) \\
\hline
\end{tabular}

[\#], criticism identifier; \#A, antecedent criticism; \#S, subsequent criticism

his theory, the progenitors of which include both his definition of 'science' [4] and belief in one 'right' way of building [3] (Fig. 2). The final group [15, 16, 17, 18, 19] contains criticisms primarily related to the development of Alexander's theory, including issues such as faulty reasoning that arise primarily from his argument that there is only one right way of building [3]. The problems identified in the second and third groups contribute to further criticisms of the implementation and outcomes of Alexander's theory.

The first group of criticisms contains two subsets of related problems. The first subset $[5,6,7,8,9]$ arises from Alexander's definition of 'science' [4] and includes accepted features in scholarly writing which are missing from the documentation of his theory. The second subset $[10,11,12]$ focuses on issues that should normally be absent from scholarly writing but are present in Alexander's texts, including the use of disparaging or biased statements, which arise equally from the definitions of 'science' [4] and belief that beauty is only achieved through the timeless way of building [3].

Alexander's canonical texts feature multiple barriers to those who wish to critically engage with his second theory, including the lack of an explicit definition of a 'pattern' [5] leaving the term ambiguous and able to encapsulate multiple pre-formal concepts (Lea 1994; Silva and Paraizo 2008). The concept of 'forces', which is central to both Alexander's first and second theories of architecture, also lack formal definition in his canonical texts. The best explanations appear in Alexander's secondary texts including The Atoms of Environmental Structure (Alexander and Poyner 1967), which implies that forces are 'tendencies', and From a set of Forces to a Form (Alexander 1966), where the only definition is found. However, even with access to these additional texts, the definition of a 'force' remains ambiguous with both 'force' and 'tendency' relying upon the other term in their definitions. This circular logic leaves the reader 


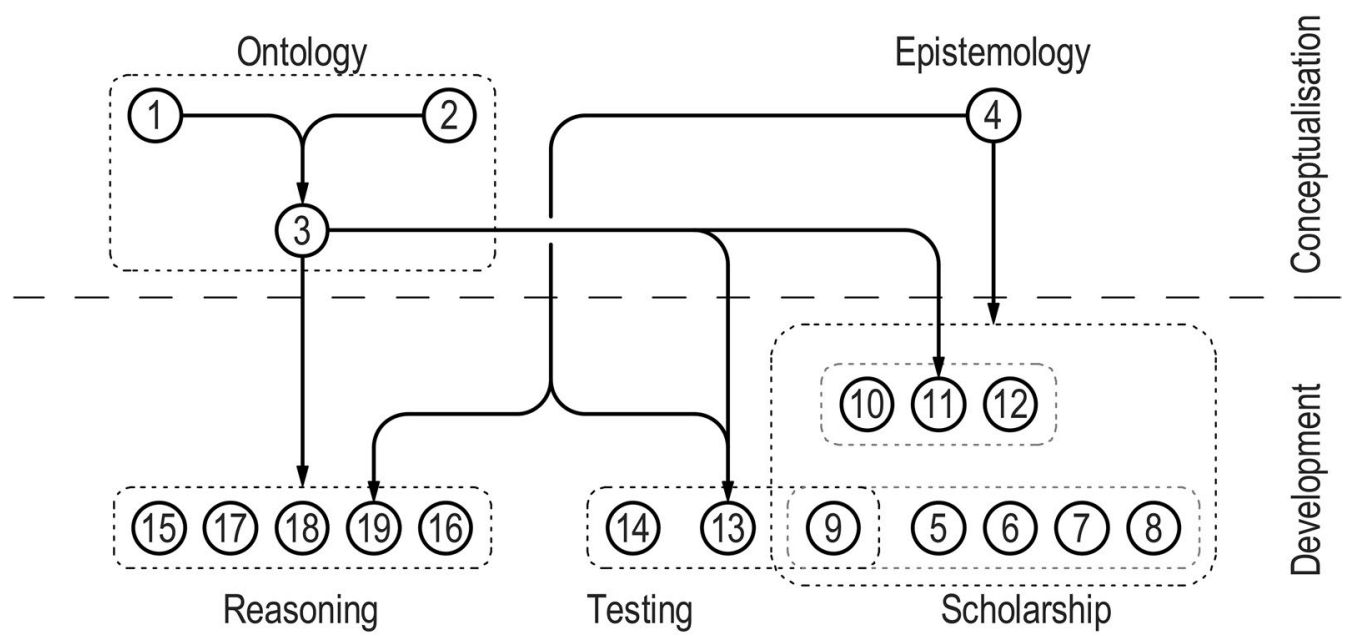

Fig. 2 Criticism connections and groupings of Alexander's second theory of architecture: development and documentation. Numbers correspond to criticism numbers in text and tables, dotted lines indicate groups and sub-groups of criticisms, arrows point from antecedent criticisms to secondary criticisms or groups of criticisms

with only implicit definitions, pieced together from poetic examples of forces. Without access to these secondary texts Alexander's second theory becomes opaque and this lack of specificity undermines his suggestion that new patterns can be developed.

Alexander's choice of visual material [6] presents another barrier to those wishing to engage with his theory. Images of his own designs which evoke the 'quality without a name' are typically blurry and poorly framed, making it difficult to discern how this quality is achieved, and without clear examples, architects are unable to adopt, analyse or critique the theory (Kohn 2002). A further weakness in documentation is Alexander's refusal to acknowledge [7] that like-minded thinkers, such as Jane Jacobs and Bernard Rudofsky, were grappling with similar problems, thereby leaving Alexander's theory intellectually isolated (Elsheshtawy 2001; Kohn 2002; Bhatt 2010). Alexander's tendency to dismiss the insights and solutions of others also gives his texts a condescending tone that further contributes to the alienation of its most likely audience, fellow architects and planners (Kohn 2002; Saunders 2002a). Each of these issues with the development of Alexander's theory can be seen as symptoms arising from its conceptualisation and his definition of 'science' [4] which rejects rigorous documentation as the 'window dressing' of 'phony' science.

The fundamental premise that beautiful places can be created by synthesising patterns into larger wholes highlights two additional criticisms [8,9] of Alexander's documentation (Lang 1994). The first of these additional criticisms is that Alexander's canonical texts devote little attention to explaining that the quality emerges from synthesising individual patterns into larger and more complete designs [8] (Salingaros 2000; Saunders 2002a). This process of synthesis is guided by the connections between patterns which unite individual patterns into a cohesive language that effectively constitutes a large graph. Yet, 38 years pass before the first attempt is made to analyse even a portion of this underlying graph structure (Park 2015). The second additional criticism is that Alexander's documentation also fails to rigorously demonstrate the fundamental premise that beautiful environments are comprised of greater numbers of patterns than the contemporary designs which are allegedly destroying the world [9]. This is significant because it has been argued that one means of validating Alexander's theory is to follow the sequence of patterns in reverse, to reveal emergent phenomena not contained in any individual pattern (Salingaros 2000). However, this approach does not provide a link between beauty and the presence of patterns, a fact which is partially rectified in Alexander's later work, A Foreshadowing of $21^{\text {st }}$ Century Art (Alexander 1993). Here 'centres' replace patterns as the source of beauty and Alexander demonstrates how the synthesis of these 'centres' can produce a larger 'whole' design, and that the most beautiful designs contain the greatest synthesis of these 'centres'.

The second subset of developmental issues resulting in 'scholarly' barriers $[10,11,12]$ that discourage engagement with Alexander's theory may also be connected conceptual issues and arise from his definition of 'science' [4] and his belief in one 'right' way of building [3]. The first manifestation of these barriers is Alexander's use of deliberately provocative statements [10] such as the claim 
that all idiosyncratic architecture is 'absurd' (Kohn 2002). These allegedly rhetorical statements were intended to activate the populace (King 1993), but instead, serve to damage Alexander's credibility (Kohn 2002; Bhatt 2010). Other examples of deliberately provocative statements [10] include Alexander's constant attacks on the "cabalistic confraternity of architects [who are] perpetuating a gigantic scam on the almost unsuspecting public" (Alexander 1990, p 11).

Alexander's statements are not only provocative but also generalising and dogmatic [11], with a proselytising tone (Broadbent 1980; Protzen 1980; Kohn 2002; Messina 2003; Walker 2003; Bhatt 2010) and they are presented in texts that physically resemble a bible (Broadbent 1980; Dovey 1990). These factors serve to evoke an air of authority that discourages dissent and critical engagement with Alexander's theory, while reinforcing the notion that there is only one 'right' way of building. Alexander's low opinion of architects, and the barriers he placed in their way, are problematic because he still envisions them playing an important role as guides to $A$ Pattern Language's participatory design processes (Bobic 1996; Tanner 2000). Ironically, the authoritative tone results in his work resembling self-help books which serves to inspire confidence among non-professionals and is suggested to partially explain the widespread popularity of A Pattern Language (Bhatt 2010).

The next group of development and documentation problems $[13,14]$ focus on Alexander's use of the term 'empirical' (and the evidence supporting his patterns) and has antecedents in his ontological [3] and epistemological positions [4]. Alexander's supporting evidence [13] has been criticised for being superficial, pseudo-scientific and little more than personal preference (Broadbent 1980; Protzen 1980; Dovey 1990; Salingaros 2000; Kohn 2002; Saunders 2002a), however much of this criticism appears to arise from Alexander's ambivalence when using the term 'empirical' (Dovey 1990). For example, in A Pattern Language Alexander likens his patterns to scientific hypotheses and states that the body of each pattern describes "the empirical background of the pattern, the evidence for its validity" (Alexander et al. 1977, $\mathrm{p}$ xi). Alexander also goes on to state that "[t]he empirical questions centre on the problem-does [the pattern] occur and is it felt in the way we have described it?-And the solution-does the arrangement we propose in fact resolve the problem" (Alexander et al. 1977, p xv). However, Dovey shows that the term empirical may be used in two different ways. The first describes a scientific process "based solely on experiment and observation" (Dovey 1990, p 4), where knowledge is the result of the rigorous testing of a hypothesis. Alternatively, the term empirical also describes "practical experience without reference to scientific principles" (Dovey 1990, p 4) where knowledge is derived from phenomenological experience. Thus, Alexander appears to desire the epistemological strength of the scientific method, but wishes to exclude the dualistic foundation that separates mind and body (Dovey 1990). Subsequently, it is argued that the majority of Alexander's patterns have never truly been tested [14]. This is because patterns early in the language require the reorganisation of socio-economic systems and the connected nature of patterns may mean that individual patterns can never be tested in isolation (Protzen 1980; Salingaros 2000). Unlike most criticisms, the potential un-testability of patterns and their languages has no antecedent in the conceptualisation of Alexander's theory. This is a criticism of the pattern language concept, which would apply to every pattern language, and the difficulty that testing a language presents, would scale proportionately with the size of each language.

The final criticisms $[15,16,17,18,19]$ of the development and documentation of Alexander's theory are issues of faulty reasoning and logic arising primarily from the existence of only one 'right' way of building [3] (Protzen 1980; Kohn 2002; Bhatt 2010). One logical problem [15] is found in Alexander's statement that a pattern "contains only the essentials which cannot be avoided if you really want to solve the problem" (Alexander et al. 1977, p xiii). Any design may be summarily dismissed for not really solving the problem, and the ability to change the definition of really solving the problem on an ad hoc basis provides Alexander with an insurmountable defence of his theory.

Alexander's insistence on returning to pre-industrial production modalities [16] comprises three examples of flawed reasoning. First, this insistence arises from Alexander's vision of a society of pure freedom and is to be achieved through an activated populace reshaping their environment through bottom-up, grass roots processes. This pre-industrial language demands hand-crafting, piecemeal development, the de-commodification of land, and an absence of external controls. However, Anders Duany-a founder of The Congress for the New Urbanism, an organisation established to implement ideas of Alexander and Jane Jacobs-argues that grass roots process are insufficient to achieve to achieve the scale of change Alexander requires. This scale of change is only possible with top down control and the guidance of expert leaders, a role that Alexander typically fulfils in his own projects (Mehaffy 2004, 2008). Second, the preindustrial production methods including a retreat from labour specialisation is unlikely to achieve a level of productivity sufficient to support a modern society. Finally, if Alexander's patterns are to be successful they must be compatible with contemporary society, which includes 
the ability to profit monetarily from one's endeavours, and Alexander's insistence on the de-commodification land runs counter to this requirement (Dovey 1990). Critics point to Alexander's insistence on forcing these requirements on a modern society as symptomatic of an ontology that ignores social, political and economic realities that establishes a connection between problems with the development and conceptualisation of the theory (Montgomery 1970; Dovey 1990; Salingaros 2000; Elsheshtawy 2001; Saunders 2002a). Meanwhile flawed reasoning also produces patterns that are incompatible with contemporary society and establishes a connection to problems with the implementation of the language.

In another example of flawed reasoning, Alexander's theory espouses pure freedom-no rules, no morals, no top-down control-yet proposes achieving this through the imposition of his own set of inviolable rules [17], because he doesn't trust the activated populace to avoid mistakes and missed opportunities (Saunders 2002a; Walker 2003; Kalb 2014). The "contradiction that freedom is to be achieved through obedience to his rules pervades Alexander's work" (Saunders 2002a, p 94). In effect, Alexander's proposal is to replace the theory and practice of modernism (which he rejects as totalitarian and controlling) with an alternative, yet equally tyrannical romanticism (Protzen 1980; Saunders 2002a).

Achieving freedom by imposing rules is not the only misalignment between the goals and methods of Alexander's theory. Alexander's second theory is intended to restore the intuitively developed and innately satisfying forms of traditional architecture. However, Alexander's careful analysis and explanation of how traditional environments arise is insufficient to restore those qualities through his own, highly systemised design process [18]. Thus, Alexander's goal of restoring the benefits of traditional procurement can only be achieved through a return to traditional procurement models (Kalb 2014). One final piece of contradictory logic is Alexander's claim that people prefer his architecture due to the feelings it evokes, while also arguing that the majority of people have compromised [19] taste, due to years of modernist brainwashing (Bornstein 2005/2006).

\section{Implementation and outcome criticisms}

The final criticisms of Alexander's theory focus on its implementation and outcomes, and have antecedents in both its development and documentation and its conceptualisation (Table 3). These criticisms can be organised into three broad groupings. The first group of implementation problems $[20,21,22]$ result from Alexander's singular vision of the one 'right' way of building [3] and allege that his patterns are too controlling and inflexible (Fig. 3). This controlling nature becomes particularly problematic as the second group of criticisms [23, 24] highlight flaws in individual patterns, which can be conceptually traced back to the testing of the theory [13]. The final group $[25,26,27,28]$ of criticisms allege that Alexander's theory fails to fulfil the objective of creating environments that embody the 'quality without a name' and these include Alexander's own rejection of his second theory of architecture.

Alexander's patterns serve as neatly packaged reminders of design wisdom that restrict architects and lay people to providing only those solutions that satisfy emotional and physical needs, while producing cohesive and contiguous environments (Davis 1983; Salingaros 2000; Saunders 2002a; Kalb 2014). However, the constraining nature of Alexander's patterns led scholars to criticise the theory for limiting the designer's creativity [20] and preventing them from pursuing agendas that differ from his (Davis 1983; Dovey 1990; Messina 2003). This complaint is certainly valid, insofar as Alexander's intention is to restrict the designer's capacity to produce radical works, in order to ensure the creation of environments that capture the quality without a name. Creativity in Alexander's theory comes from adapting patterns to serve local conditions, rather than developing new solutions, and this allows each pattern to generate an infinite number of unique designs (Alexander et al. 1967, 1977; Salingaros 2000). However, "[b]y staying within the pattern language you will never be able to produce a design that is radically different from the design of any other pattern language user, no matter what the personal desires or what the local conditions are" (Protzen 1980, p 292). This criticism of the raison dêtre of Alexander's second theory echoes the sentiments of many architects who rejected the theory (Dovey 1990; Salingaros 2000; Messina 2003; Bhatt 2010).

The restrictive nature of Alexander's patterns are also problematic for their potential to override the actual needs and aesthetic preferences of language users [21]. Alexander's affordable housing project in Mexicali required 2 weeks of experimentation before he decided on the colour to paint the cornice, despite clients and staff members who believed the design should be all white, or simply didn't understand the necessity of ensuring the colour was 'just right' [22]. As a further example, Alexander's inclusion of the romanticised sleeping arrangements of pattern 188 'Bed Alcoves' in his social housing experiment in Lima produced "stuffy, claustrophobic little cells" (Broadbent 1980, p 235) where the residents prefer the bedrooms of traditional shanties which provide ample ventilation. This pattern is both contrary to user preferences and unfit for its purpose. In this sense Alexander "occasionally exhibits a fetish for form that would rival the most fastidious of the high style architects... 
Table 3 Criticisms of Alexander's second theory of architecture: implementation and outcomes

\begin{tabular}{|c|c|c|c|c|c|}
\hline [\#] & Issue & A\# & Criticism & S\# & Source \\
\hline 20 & Restricting & 3 & Patterns disallow radical solutions & - & $\begin{array}{l}\text { (Broadbent 1980; Protzen 1980; Davis 1983; Dovey 1990; } \\
\text { Salingaros 2000; Kohn 2002; Saunders 2002a; Messina } \\
\text { 2003; Mehaffy 2007; Bhatt 2010; Montgomery 1970) }\end{array}$ \\
\hline 21 & Restricting & 3,15 & The 'correct' use of patterns can overrule user preferences & - & (Dovey 1990; Saunders 2003) \\
\hline 22 & Restricting & 3 & Alexander insists on every detail being 'correct' & 26 & (Dovey 1990) \\
\hline 23 & Flawed & 13,16 & Some patterns prescribe flawed solutions & - & (Broadbent 1980; Gelernter 2000; Salingaros 2000) \\
\hline 24 & Flawed & 13 & Some patterns are contradictory and incompatible & - & (Protzen 1980; Saunders 2002a) \\
\hline 25 & Unsuccessful & 9,13 & $\begin{array}{l}\text { Patterns are not required to create beautiful places and } \\
\text { ugly places can be created using patterns }\end{array}$ & - & $\begin{array}{l}\text { (Broadbent 1980; Protzen 1980; Kohn 2002; Walker 2003; } \\
\text { Seamon 2006; Kalb 2014) }\end{array}$ \\
\hline 26 & Unsuccessful & 22 & $\begin{array}{l}\text { Patterns produce awkward and poorly constructed } \\
\text { buildings }\end{array}$ & - & (Kohn 2002; Seamon 2006) \\
\hline 27 & Unsuccessful & 9,13 & A Pattern Language lacks a focus on geometry & - & (Pontikis 2010) Alexander in (Grabow 1983) \\
\hline 28 & Unsuccessful & - & Alexander's pattern language is cumbersome to use & - & (Salingaros 2000) \\
\hline
\end{tabular}

[\#], criticism identifier; \#A, antecedent criticism; \#S, subsequent criticism

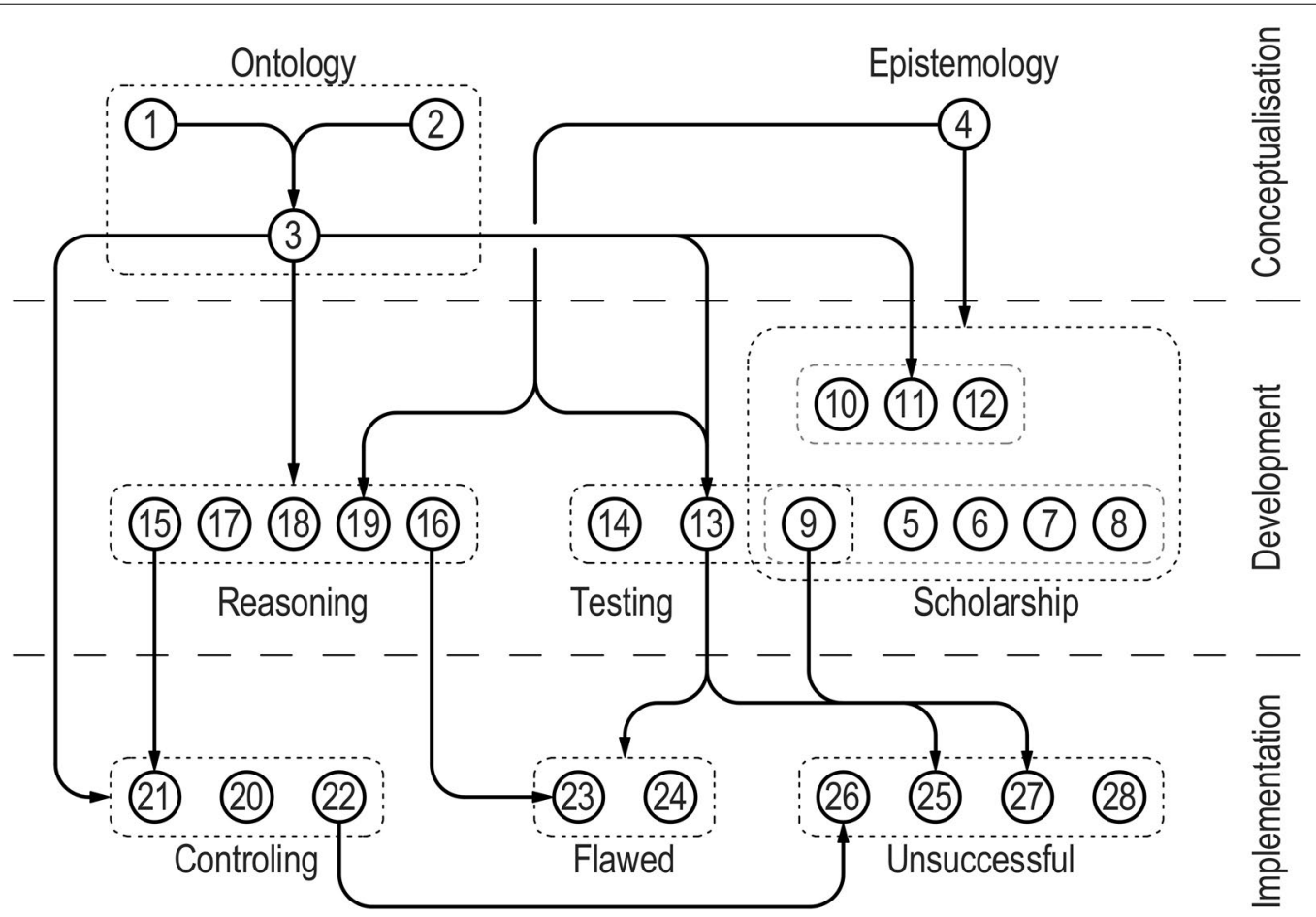

Fig. 3 Criticism connections and groupings of Alexander's second theory of architecture: Implementation and outcomes. Numbers correspond to criticism numbers in text and tables, dotted lines indicate groups and sub-groups of criticisms, arrows point from antecedent criticisms to secondary criticisms or groups of criticisms

[and that] Alexander's insistence in getting every detail 'right' serves to undercut the larger paradigmatic change by leaving the dweller dependent on nothing more than a different kind of aesthetic expert" (Dovey 1990, p 7). Thus, problems with the implementation of Alexander's theory $[20,21,22]$ can be traced back to problems with theory development [15], and both implementation and developmental problems can be traced back to the conceptualisation of the theory [3] as the one 'right' way of building.

The second group of problems $[23,24]$ focus on the flaws and contradictions in individual patterns resulting from ideologically driven testing [13] and which become particularly problematic when patterns override 
user preferences. The flaws in patterns [23] are partially the result of some patterns aging poorly while others were bad from their inception and include those that are incompatible with modern society [16] (Broadbent 1980; Gelernter 2000; Saunders 2002a). The Peruvian 'bed alcoves' mentioned above provide an example of a pattern that was flawed in its application. Further examples of flawed patterns include those detailing economic and construction requirements which are not compatible with modern society (Dovey 1990; Salingaros 2000) and those related to vehicular traffic. These vehicular patterns may have been appropriate at the time Alexander's theory was published, but are no longer capable of serving the greater densities of vehicular traffic of today's society (Gelernter 2000). In addition to containing flawed content, a further problem with implementing Alexander's theory is that some patterns appear to directly contradict other patterns [24] despite the connections indicating that those patterns should synthesise into a more complete whole (Protzen 1980; Saunders 2002a). This situation presents a challenge for designers as Alexander provides no guidance for determining which pattern should take precedence. A looser interpretation of contradictory patterns might allow both be combined into a single design, however this also risks misinterpreting the essence of each pattern and producing a flawed outcome.

The final group of four criticisms [25, 26, 27, 28] state that Alexander's theory fails to achieve the objective of creating beautiful places. These criticisms include the observation that it is possible to create beautiful, lively places without using any of Alexander's patterns [25] and equally possible to create ugly and dead places using them (Broadbent 1980; Protzen 1980; Walker 2003; Kalb 2014; Kohn 2002). Several real and simulated projects led by Alexander, and using his patterns, either fail to live up to his expectations (Alexander et al. 1978; Seamon 2006), or are so poorly constructed and awkward in appearance [26] that they could not be regarded as beautiful under any traditionally derived definition (Kohn 2002; Seamon 2006). As previously noted, Alexander ultimately rejected his second theory of architecture citing a lack of focus on geometrical considerations [27] which diminished its ability to generate beautiful places (Grabow 1983; Pontikis 2010). The final criticism that Alexander's pattern language is cumbersome to use [28] echoes the view that patterns cannot be empirically tested, in that both are criticisms of the pattern language concept and lack precursors in Alexander's conceptualisation of the theory.

\section{Conclusion}

The preceding sections illustrate how 28 criticisms of Alexander's second theory of architecture can be categorised hierarchically, formed into thematic groups, and their relationships mapped to reveal that many issues affecting the development and implementation of the theory can be connected to Alexander's idiosyncratic ontological and epistemological positions. For instance, 12 criticisms [10,11, 12, 13, 15, 16, 17, 18, 19, 20, 21, 22] $(43 \%)$ are directly connected to high level ontological problems $[1,2,3]$ and a further 5 criticisms $[23,24,25$, $26,27](18 \%)$ are directly connected to these secondary problems. Furthermore, 10 criticisms $[5,6,7,8,9,10,11$, $12,13,18](36 \%)$ are directly connected to Alexander's epistemology [4] and a further 4 criticisms [23, 24, 25, 27] (14\%) are directly connected to these secondary criticisms. Surprisingly, only 2 criticisms $[14,28](7 \%)$ relate directly to the pattern language concept rather than criticisms of Alexander's ontological and epistemological positions, and these criticisms are amongst the more speculative.

As this mapping of criticisms shows, many perceived problems with Alexander's theory are directly or indirectly connected to high level conceptual issues. The thematic grouping of these issues indicates that Alexander's theory: (i) embraces an ontology that confuses objective and subjective phenomena, rejects pluralistic values and alternate experiences, ignores political and social realities, and accepts only one 'right' way of building. This theory also (ii) depends on an idiosyncratic definition of 'science' that relies on ambiguous interpretations of what constitutes empirical research and eschews the scientific practices of rigorous testing and documentation. The development of Alexander's theory is criticised for: (i) failing to provide explicit definitions of terms, not engaging with scholarly literature, or providing traditional empirical validation for claims, and thereby failing to meet expected standards of scholarly writing. It also (ii) fails to engage in rigorous testing of patterns, and (iii) includes significant examples of flawed reasoning and logical problems. The implementation of Alexander's theory is also criticised for: (i) being overly controlling and restrictive, (ii) including flawed patterns and recommendations for design, and ultimately, (iii) failing to accomplish the intended goal of creating beautiful and whole designs.

Mapping criticisms into thematic groups reveals familiar issues for those experienced with Alexander's theory, however this grouping of criticisms has not previously been so explicitly identified. These considerations are often overlooked by many readers of Alexander's theory who merely see a recipe book, of conveniently formatted, seemingly well-intentioned, humanist solutions to the challenges of contemporary design. Indeed, its popularity amongst owner-builders and home designers may largely reside in the fact that much of a pattern language remains useful, even if the reader remains unaware of these 
criticisms. However, by explicitly mapping and grouping these criticisms into common themes, novice readers may develop a deeper understanding of the theory's weaknesses. Meanwhile, veteran users of the language may benefit from a deeper understanding of how problems encountered when attempting to design with the language are connected to issues with the development and conceptualisation of the theory.

The identification and organisation of these criticisms suggests three possible directions for the future of pattern languages. The first is to consider A Pattern Language as a historical artefact worthy of further exploration. The second investigates the concept of pattern languages including whether or not they can be rigorously tested and whether they are practical design methodologies, the third is to develop new pattern languages without the restrictions of Alexander's ontological and epistemological positions. This final avenue for research has the potential to enable a paradigm shift in architectural theory, but only if patterns can be rigorously tested. Ultimately, the elusive nature of the 'quality without a name' may prevent the rigorous testing of patterns, however, even in this eventuality patterns remain powerful phenomenological design tools "For the fact is most architects, most of the time, have worked according to patterns" (Broadbent 1980, p 252). While these patterns largely remain informal, Alexander's second theory of architecture offers the potential to formalise complex phenomena into an easily digestible format which is accessible to non-professionals. Formalising patterns in this way may facilitate improved communication between architects and clients by providing each party with a deeper means of understanding the values and vision of the other.

\section{Authors' contributions}

MJD: primary author. MJO: research supervisor. Both authors read and approved the final manuscript.

\section{Acknowledgements}

This research was supported by an Australian Government Research Training Program Scholarship.

\section{Competing interests}

The authors declare that they have no competing interests.

\section{Availability of data and materials}

Not applicable.

\section{Consent for publication}

Both authors approve this manuscript for publication.

\section{Ethics approval and consent to participate} Not applicable.

\section{Funding}

This research was supported by an Australian Government Research Training Program Scholarship.

\section{Publisher's Note}

Springer Nature remains neutral with regard to jurisdictional claims in published maps and institutional affiliations.

Received: 3 September 2017 Accepted: 5 December 2017

Published online: 19 December 2017

\section{References}

Adams D, Tiesdall S (2007) Introduction to the special issue: the vital city. Town Plan Rev 78(6):671-679

Alexander C (1964) Notes on the synthesis of form. Harvard University Press, Cambridge

Alexander C (1966) From a set of forces to a form. In: Kepes G (ed) The man made object. Studio Vista, London, pp 96-107

Alexander C (1979) The timeless way of building. Oxford University Press, New York

Alexander C (1990) Letter to the editor. Progres Archit 77(April):11

Alexander C (1993) A foreshadowing of 21st century art. Oxford University Press, New York

Alexander C (1996) Patterns in architecture. In: Anderson L, Copelin J (eds) OOPSLA—conference on object oriented programming systems languages and applications. Association for Computing Machinery, San Jose

Alexander C (2002a) The nature of order: Christopher Alexander responds to William Saunders's review of his latest book. http://www.architecturalrecord.com/articles/11450-the-nature-of-order?page=1. Edited version published in 2002 Architectural Record 190(12): 57. Accessed 14 June 2017

Alexander C (2002b) The nature of order: an essay on the art of building and the nature of the universe. Vol I, The phenomenon of life. Centre for Environmental Structure, Berkley

Alexander C (2002c) The nature of order: an essay on the art of building and the nature of the universe. Vol II, The process of creating life. Centre for Environmental Structure, Berkley

Alexander C (2004) The nature of order: an essay on the art of building and the nature of the universe. Vol IV, The luminous ground. Centre for Environmental Structure, Berkley

Alexander C (2005) The nature of order: an essay on the art of building and the nature of the universe. Vol III, A vision of a living world. Centre for Environmental Structure, Berkley

Alexander C, Eisenman P (1982) Contrasting concepts of harmony in architecture. In: Katarxis No 3, 2004

Alexander C, Poyner B (1967) The atoms of environmental structure. Center for Planning and Development Research, Berkeley

Alexander C, Wilson CSJ, March L, Norberg-Schultz C, Brawne M (1967) Design innovation: discussion. Progres Archit 48(November):126-131

Alexander C, Silverstien M, Angel S, Ishikawa S, Abrams D (1975) The Oregon experiment. Oxford University Press, New York

Alexander C, Ishikawa S, Silverstienm M (1977) A pattern language: towns, buildings, construction. Oxford University Press, New York

Alexander C, Nies H, Anninou A, King I (1978) A new theory of urban design. Oxford University Press, New York

Bhatt R (2010) Christopher Alexander's pattern language: an alternative exploration of space-making practices. J Archit 15(6):711-729

Bobic M (1996) A timeless pattern language: on the translation of a pattern language. Archis 7:54-60

Bornstein E (2005/2006) An interview with Christopher Alexander. The Structurist 2005/2006 (45/46): 4-21

Broadbent G (1980) Pattern language. Des Stud 1(4):252-253

Clavan B (1979) Christopher Alexander and the pattern language. Archit Urban 12(11):78-98

Davis H (1983) Individual houses in groups: the pattern language in a teaching studio. J Archit Educ 36(3):14-19

Dovey K (1990) The pattern language and its enemies. Des Stud 11(1):3-9

Elsheshtawy Y (2001) Searching for theory in Christopher Alexander's intellectual roots. Archit Sci Rev 44(4):395-403

Gelernter M (1983) Christopher Alexander and the pattern language. Archit J $1: 17-21$

Gelernter M (2000) Sun-filled window seats. Archit Res Q 4(2):190-192 
Grabow S (1983) Christopher Alexander: the search for a new paradigm in architecutre. Oriel Press, Stocksfield

Hermann C (2004) Architecture and programming: generative design. In: Williams K, Cepeda FD (eds) Nexus V: architecture and mathematics. Kim Williams Books, Florence, pp 105-116

Jacobs J (1961) The death and life of great American cities. Random House, New York

Kalb J (2014) Life in design: Christopher Alexander and the nature of order. Int J Archit Res 8(2):94-98

Kaplan S, Dale FD, Kaplan R (1987) Patterns as hypotheses: an empirical test. In: Harvey J, Henning D (eds) Public environments. EDRA, Washington D.C., pp 188-193

King IF (1993) Christopher Alexander and contemporary architecuture. Archit Urban, Tokyo

Kohn W (2002) The lost prophet of architecture. Wilson Quarterly Summer, p 26-34

Lang J (1994) Urban design the American experience. Wiley, New York

Lea D (1994) Christopher Alexander: an introduction for object-oriented designers. Softw Eng Notes 19(1):39-46

Lynch K (1960) The image of the city. MIT Press, Cambridge

Mehaffy MW (2004) A conversation with Andrés Duany. Katarxis No 3. http:// www.katarxis3.com/Duany.htm

Mehaffy MW (2007) Notes on the genesis of wholes: Christopher Alexander and his continuing influence. Urban Des Int 12(1):41-49

Mehaffy MW (2008) Generative methods in urban design: a progress assessment. J Urban 1(1):57-75

Messina J (2003) Architecture: some musings on the state of the art. J Southwest 45(1/2):1-7

Montgomery R (1970) Pattern language. Archit Forum 132(1):52-59

Park Y (2015) The network of patterns: creating a design guide using Christopher Alexander's pattern language. Environ Plan B Plan Des 42(4):593-614
Pontikis K (2010) Teaching Christopher Alexander's theoretical framework in a capstone interior design studio. Des Princ Pract 4(3):407-425

Protzen JP (1980) The poverty of the pattern language. Des Stud 1(5):291-295

Rapoport A (1969) House form and culture. Prentice-Hall, New Jersey

Rapoport A (1982) The meaning of the built environment: a nonverbal communication approach. Sage Publications, Beverly Hills

Rudofsky B (1964) Architecture without architects: a short introduction to nonpedigreed architecture. Mesuem of Modern Art, New York

Salingaros NA (2000) The structure of pattern languages. Archit Res Q $4(2): 149-161$

Saunders W (2002a) Commentary: ever more popular, ever more dogmatic: The sad sequel to Christopher Alexander's work. Archit Rec 190(5):93-96

Saunders W (2002b) A pattern language by Christopher Alexander. Harvard Design Magazine Winter/Spring, 16: 74-78

Saunders W (2003) The nature of order II: William Saunders responds to Christopher Alexander's letter. http://www.architecturalrecord.com/ articles/12371-the-nature-of-order-ii?. Accessed 14 June 2017

Seamon D (2006) Clarifying and evaluating Alexander's theory of wholeness by interpreting his approach as a tetrad of activity. In: Annual meetings of the International Association for Environmental Philosophy, Philadelphia, PA, October, 2006

Silva EM, Paraizo C (2008) Urban projects database based on Alexander's pattern language: the case of Favela-Bairro. Int J Archit Comput 6(3):261-277

Tanner K (2000) The influence of school architecture on academic achievement. J Educ Administration 38(4):309-330

Veloso PLA (2014) Cybernetic diagrams: design strategies for an open game. Int J Archit Comput 12(4):379-397

Walker B (2003) Another kind of science: Christopher Alexander on democratic theory and the built environment. Can J Political Sci 36(5):1053-1072

\section{Submit your manuscript to a SpringerOpen ${ }^{\odot}$ journal and benefit from:}

- Convenient online submission

- Rigorous peer review

- Open access: articles freely available online

- High visibility within the field

- Retaining the copyright to your article

Submit your next manuscript at $\boldsymbol{\nabla}$ springeropen.com 